\title{
IMPACTOS AMBIENTAIS HIDROLÓGICOS OCASIONADOS PELO DESFLORESTAMENTO METROPOLITANO: PETRÓPOLIS, RJ
}

\author{
Tamara Magalhães da Silva \\ Graduanda em Ciências Biológicas pela Universidade do Estado do Rio de Janeiro (UERJ) \\ Estagiária do laboratório de Ecologia de Rios e Córregos (LERC) - RJ - Brasil \\ $\triangle$ tama.magalhaes@gmail.com \\ Thereza Cristina Ferreira Camello \\ Doutora em Ciências Médicas - Biomédica - Microbiologista \\ Hospital Universitário Pedro Ernesto \\ (UERJ/ OUERJ/ ONU/ UN-Habitat) - RJ - Brasil \\ Josimar Ribeiro de Almeida \\ Doutor - Professor Universidade do Estado do Rio de Janeiro (UERJ) \\ Pesquisador Senior Centro de Engenharia Nuclear/USP - RJ - Brasil
}

\begin{abstract}
Resumo:
A expansão urbana na região de Petrópolis é decorrente de intenso desmatamento para moradia e outras atividades antrópicas. Desflorestamento é a causa principal de desequilíbrios ecológicos, resultando em: inundações, diminuição da porosidade do solo e desertificação. Através da técnica de AIA de análise semiqualitativa estudou-se possíveis prejuízos e benefícios da expansão urbana na localidade, se as mudanças eram passíveis ou não de ocorrência e seu nível de impactação. Observou-se que a probabilidade de ocorrências de prejuízos era muito maior que a de benefícios. O resultado corrobora a literatura, sendo assim, foi visto que a vegetação possui papel importante no controle hídrico da localidade, e também na integridade física e química do solo. A probabilidade de consequências catastróficas, por conta do desmatamento, é extremamente alta, e mesmo as consequências de médio porte possuem capacidade de impactos ambientais que tendem a ser irreversíveis. O desmatamento intensifica as consequências das grandes precipitações frequentes no verão do Estado do Rio de Janeiro, logo, quanto maior o desmatamento, maior a probabilidade de eventos recorrentes e intensos resultantes das grandes precipitações. Logo, é necessário um controle da expansão urbana na região para diminuir o impacto ambiental hídrico na região.
\end{abstract}

Palavras-chave: Desflorestamento; Expansão urbana; Alagamento; Deslizamentos de terra.

\section{HYDROLOGICAL ENVIRONMENTAL IMPACTS CAUSED BY DEFORESTATION UNDERGROUND: PETROPOLIS, RJ}

\begin{abstract}
:
Urban expansion in Petropolis region is due to massive deforestation for housing and other human activities. Deforestation is the main cause ecological imbalances, resulting in:
\end{abstract}


flooding, decrease in porosity and desertification of soil. By AIA semi-qualitative technique analysis it studied possible losses and benefits of urban expansion in the locality, if changes were likely or not of occurrence and their level of impaction. It was observed that the probability of occurrence of damage was much higher than that of benefits. The result corroborates the literature, therefore, has been seen that vegetation plays an important role in water control of the town, and also in the physical and chemical soil. The probability of catastrophic consequences, due to deforestation, is extremely high, and even mid-sized consequences have capacity of environmental impacts that are likely to be irreversible. Deforestation intensifies the consequences of major frequent rainfall in the summer of the State of Rio de Janeiro, so the higher the deforestation, the greater the likelihood of recurrent and intense rainfall events resulting from large. Therefore, it is necessary to control urban sprawl in the region to reduce water environmental impact in the region.

Keywords: Deforestation; Urban sprawl; Flooding; Landslides.

\title{
IMPACTOS AMBIENTALES HIDROLÓGICOS CAUSADAS POR LA DEFORESTACIÓN METROPOLITANA: PETRÓPOLIS, RJ
}

\begin{abstract}
Resumen:
La expansión urbana en la región de Petrópolis se debe a la deforestación masiva de viviendas y otras actividades humanas. La deforestación es la principal causa desequilibrios ecológicos, lo que resulta en: inundaciones, disminución de la porosidad y la desertificación de los suelos. Por AIA análisis semiqualitativa técnica estudió posibles pérdidas y beneficios de la expansión urbana de la localidad, si los cambios eran probables o no de ocurrencia y su nivel de impacto. Se observó que la probabilidad de ocurrencia de daño fue mucho mayor que la de beneficios. El resultado corrobora la literatura, por lo tanto, se ha visto que la vegetación desempeña un papel importante en el control de agua de la ciudad, y también en el suelo física y química. La probabilidad de consecuencias catastróficas, debido a la deforestación, es extremadamente alta, e incluso consecuencias medianas tienen la capacidad de los impactos ambientales que puedan ser irreversibles. Deforestación intensifica las consecuencias de gran lluvias frecuentes en el verano del Estado de Río de Janeiro, por lo que cuanto mayor es la deforestación, mayor es la probabilidad de eventos recurrentes e intensas lluvias que resultan de gran tamaño. Por lo tanto, es necesario controlar la expansión urbana en la región para reducir el impacto ambiental del agua en la región.
\end{abstract}

Palabras clave: Deforestación; Expansión urbana; Inundaciones; Deslizamientos de tierra. 


\section{INTRODUÇÃO}

O desmatamento é uma das intervenções humanas mais prejudiciais à sustentabilidade ambiental, podendo culminar em desequilíbrio físico, químico e ecológico. A vegetação possui papel fundamental na manutenção do microclima, principalmente no processo hidrológico da bacia hidrográfica. As principais consequências do desmatamento são a perda de biodiversidade, a degradação do solo, mudanças climáticas e na hidrografia. (FERREIRA et al., 2005; FEARNSIDE et al., 2006)

Solos florestados possuem uma capacidade de infiltração maior do que solos descobertos, mas uma quantidade menor de água chega ao solo florestado que no solo descoberto, por conta de uma parcela dessa água ser interceptada pela copa das árvores. Por esse motivo, áreas florestadas apresentam menor infiltração, no entanto, no solo descoberto podem ocorrer alterações nas propriedades do solo por conta do impacto das gotas de chuva, ocasionando diminuição de infiltrações (ALMEIDA et al., 2013).

Em áreas florestadas o microclima criado se deve principalmente ao controle da evapotranspiração. A água evaporada é transportada a outros locais por correntes de ventos, e a floresta mais densa contribui na diminuição na evaporação do solo, amenizando temperatura e diminuído as correntes de ventos. Há também, a redução de vazões de rios, por conta da evaporação que fica interceptada no dossel, sendo assim um desmatamento leva a uma maior vazão dos rios. A retenção de água, também, promove redução na ocorrência de inundações, a vegetação contribui para o aumento da porosidade e favorece a liberação contínua de água em níveis mais controlados, mesmo em épocas de menos chuvas. (ALMEIDA et al., 2013)

Petrópolis é uma das quatro glebas disjuntas que constituem a APA Petrópolis, criada em1982, pelo Decreto Federal 87.561, de 13/09/82 e oficializada em 1992. É a primeira APA federal criada no país (BAPTISTA e CALIJURI, 2007).

Durante muito tempo a expansão urbana na região metropolitana de Petrópolis foi regulada pelo plano urbanístico elaborado pelo major Koeler por volta do século XVIII, com o objetivo de se manter o equilíbrio entre a expansão urbana e a preservação do ambiente. Com o tempo tais regras elaboradas começaram a ser desrespeitadas, e logo houve casos de grandes áreas desmatadas, para dar lugar a culturas agrícolas, pastagens e ocupação imobiliária, oferecendo riscos a própria população ali vivente (ALMEIDA et al., 2013) (GUERRA et al., 2007). 
Hoje a ocupação é caracterizada por uma junção de áreas de ocupação desordenada, e outras de ocupação "orientada", feita por um parcelamento e distribuição de lotes sem critérios urbanísticos ou parcialmente dentro das regulamentações municipais. A ocupação apresenta um nível acentuado de habitações com características de sub-habitação e favelização, em áreas até então valorizadas pelo mercado imobiliário. (BAPTISTA e CALIJURI, 2007).

O solo da bacia hidrográfica estudada possui uma boa capacidade de infiltração da água, sendo composta médio-argilosa ou franco-argilosa, o desflorestamento reduz a quantidade de água captada da chuva pela transpiração e evaporação da vegetação, aumentando o volume escoado e desbalanceado o balanço hídrico da bacia. E a baixa taxa de água evapotranspirada acaba sendo transferida para outras regiões pelas correntes de ar, reduzindo o volume de água total disponível no local provocando a desertificação (ALMEIDA et al., 2013).

Na região de Petrópolis há alta incidência de chuvas, com o desmatamento, houve um aumento na taxa de água superficiais de escoamento, causando assim processos erosivos e deslizamentos de terra (BAPTISTA e CALIJURI, 2007). A avaliação desses impactos é fundamental para identificar os efeitos esperados de atividades e projetos no ambiente (biofísico e social), e principalmente, avaliar meios e medidas necessárias para monitorar e minimizar estes impactos. Para isso é necessário o estudo de caso da situação ambiental na presença e na ausência de uma atividade, e assim saber se o projeto é passível ou não de aprovação (MOREIRA, 1985).

\section{METODOLOGIA}

Foi utilizada a metodologia de AIA (avaliação de impactos ambientais) que tem como objetivo principal determinar se o projeto é passível ou não de causar danos ao meio ambiente, e se ocasionar prejuízos ao meio ambiente, é feita a analise onde será levado em conta o benefício do projeto para a aprovação do mesmo (MOREIRA, 1985).

Como não é possível obter números reais de uma grande gama de impactos e riscos, foram usadas todas as informações disponíveis a respeito do evento para se elaborar possíveis consequências relativas ao ambiente estudado. 
Nesse trabalho foi usado a técnica de abordagem semiqualitativa para determinar os impactos e riscos prováveis do desmatamento na região.

Nesse processo foi estudado o grau de consequência e probabilidade de ocorrência dos eventos, sendo cada um deles pontuados com o grau de impactação referente. Não sendo totalmente acurada a real magnitude ou de ocorrência, mas tendo o objetivo de estar mais próximo possível da realidade.

São utilizados cinco níveis de severidade - 1-Insignificante, 2-Menor, 3-Moderado, 4Maior e 5-Catastrófico. Nas consequências foram consideradas tanto impactos ambientais quantos riscos ambientais.

Foram separadas em categorias gerais (Quadro 1) e pontuais (Quadros de 2 a 5), sendo as pontuais, desenvolvidas sobre pontos de maiores importâncias.

Quadro 1 - Medidas qualitativas das consequências dos eventos gerais.

\begin{tabular}{|c|c|l|}
\hline Nível & Valor & \multicolumn{1}{|c|}{ Características } \\
\hline Insignificante & 1 & $\begin{array}{l}\text { Não impactado, sem mudanças homeostáticas no } \\
\text { ambiente. A mudança possui baixo valor de impacto } \\
\text { e/ou é recuperável em pouco tempo. Baixa/nenhuma } \\
\text { detecção dos eventos. }\end{array}$ \\
\hline Menor & 2 & $\begin{array}{l}\text { Impactos homeostáticos de baixo valor, a curto prazo } \\
\text { há mudanças no ecossistema local. Mudanças com } \\
\text { aspecto de impacto natural. Potencial de detecção de } \\
\text { impacto baixo. }\end{array}$ \\
\hline Moderado & 3 & $\begin{array}{l}\text { Impacto a longo prazo, com alteração pontual no } \\
\text { ecossistema (espécies não ameaçadas), podendo } \\
\text { contribuir para efeito sinérgico. Comprometimento da } \\
\text { saúde humana improvável. }\end{array}$ \\
\hline Catastrófico & 5 & $\begin{array}{l}\text { Dano ecológico grande, ocorrência de uma ou mais } \\
\text { espécies se tornarem ameaçadas. Sustentabilidade do } \\
\text { ecossistema prejudicado. Efeito sinérgico moderado. } \\
\text { Saúde humana pode ser afetada. }\end{array}$ \\
\hline Maior & $\begin{array}{l}\text { Extinção de espécie(s). Pouca chance de reversão do } \\
\text { impacto. Contribui grandiosamente para o efeito } \\
\text { sinérgico. Saúde humana provavelmente afetada. }\end{array}$ \\
\hline
\end{tabular}

Fonte: ALMEIDA et al., 2013 
Os quadros de 2 a 4 apresentam critérios específicos para medidas qualitativas das consequências dos eventos.

Quadro 2 - Ecossistema

\begin{tabular}{|c|c|l|}
\hline Nível & Valor & \multicolumn{1}{|c|}{ Características } \\
\hline Insignificante & 1 & $\begin{array}{l}\text { Efeitos adversos diminutos, poucas espécies afetadas a } \\
\text { curto-prazo. Reversíveis de imediato. }\end{array}$ \\
\hline Menor & 2 & $\begin{array}{l}\text { Mudança no padrão de vida de determinadas espécies, } \\
\text { danos reversíveis a curto prazo. }\end{array}$ \\
\hline Moderado & 3 & $\begin{array}{l}\text { Migração e perda de habitats em pequenas localidades, } \\
\text { potencial dano ao ecossistema (remoção de vegetação), } \\
\text { modificação do solo (drenagem), danos reversíveis a } \\
\text { médio prazo de de }\end{array}$ \\
\hline Maior & 4 & $\begin{array}{l}\text { Migração, destruição esparsa de habitats, morte de } \\
\text { animais, perda de espécies reversíveis, grande } \\
\text { modificação do solo, danos reversíveis somente com a } \\
\text { colaboração de programas, a longo prazo. }\end{array}$ \\
\hline Catastrófico & 5 & $\begin{array}{l}\text { Morte de grande número de indivíduos (flora e fauna), } \\
\text { grande destruição da vegetação, solo sofre } \\
\text { modificações irreversíveis. }\end{array}$ \\
\hline
\end{tabular}

Fonte: ALMEIDA et al., 2013

Quadro 3 - Paisagem

\begin{tabular}{|c|c|l|}
\hline Nível & Valor & \multicolumn{1}{|c|}{ Características } \\
\hline Insignificante & 1 & $\begin{array}{l}\text { Pequenas mudanças na paisagem reversíveis a curto } \\
\text { prazo. }\end{array}$ \\
\hline Menor & 2 & $\begin{array}{l}\text { Mudanças consideráveis, mas que por meio natural ou } \\
\text { por intervenções são reversíveis }\end{array}$ \\
\hline Moderado & 3 & $\begin{array}{l}\text { Mudanças causam transformação do ambiente, } \\
\text { podendo causar mudança no microclima local. Chance } \\
\text { de reversão a longo prazo }\end{array}$ \\
\hline Maior & 4 & $\begin{array}{l}\text { Impacto ambiental extenso, grande retirada de } \\
\text { vegetação. Impacto físico no solo causada pelas } \\
\text { chuvas. Dano ecológico amplo, pouquíssimas chances }\end{array}$ \\
\hline
\end{tabular}




\begin{tabular}{|l|l|l|}
\hline & & de reversão. \\
\hline Catastrófico & 5 & $\begin{array}{l}\text { Destruição da floresta, que pode gerar problemas } \\
\text { físicos e químicos no solo da região. Danos } \\
\text { irreversíveis. }\end{array}$ \\
\hline
\end{tabular}

Fonte: ALMEIDA et al., 2013

Quadro 4 - Regime hídrico

\begin{tabular}{|c|c|l|}
\hline Nível & Valor & \multicolumn{1}{|c|}{ Características } \\
\hline Insignificante & 1 & Aumento da capacidade de infiltração. \\
\hline Menor & 2 & $\begin{array}{l}\text { Infiltração pode afetar positivamente o escoamento } \\
\text { sub-superficial. Capacidade de retenção de água no } \\
\text { solo é pouco comprometida, alimentação mais rápida } \\
\text { dos cursos d'água em períodos de chuva. }\end{array}$ \\
\hline Moderado & 3 & $\begin{array}{l}\text { Variações de temperatura e umidade do ar, } \\
\text { evapotranspiração é afetada consideravelmente, } \\
\text { diminuição ainda maior da capacidade de retenção de } \\
\text { água no solo, cursos d'água podem sofrem erosões. }\end{array}$ \\
\hline Maior & 4 & $\begin{array}{l}\text { Evapotranspiração é afetada, microclima é quebrado, } \\
\text { causa mudanças no ciclo de água no local, cursos } \\
\text { d'água sofrem erosões pela chuva, podendo ainda } \\
\text { haver deslizamentos e/ou inundações. }\end{array}$ \\
\hline Catastrófico & 5 & $\begin{array}{l}\text { Ciclo hidrológico é modificado, inundações recorrentes } \\
\text { em épocas de chuva intensa, formações de sulcos no } \\
\text { solo, ajudando a infiltrações de água, deslizamentos } \\
\text { ocorrem quando a quantidade de água infiltrada é } \\
\text { menor que a quantidade precipitada, assoreamento de } \\
\text { rios. }\end{array}$ \\
\hline
\end{tabular}

Fonte: ALMEIDA et al., 2013

Quadro 5 - Medidas qualitativas dos fatores de risco dos eventos

\begin{tabular}{|c|c|l|}
\hline Nível & Valor & \multicolumn{1}{|c|}{ Características } \\
\hline Insignificante & 1 & $\begin{array}{l}\text { Pequenos acidentes de trabalho durante a derrubada, } \\
\text { ferimentos leves. }\end{array}$ \\
\hline Menor & 2 & Acidentes de trabalho, falta de equipamentos pessoais \\
\hline
\end{tabular}




\begin{tabular}{|c|c|l|}
\hline Moderado & 3 & $\begin{array}{l}\text { de segurança causando ferimentos médios. } \\
\text { Acidentes médios a graves de trabalho, pequenas } \\
\text { emissões de gases do efeito estufa, pequenas erosões } \\
\text { causam falhas no terreno. Baixo perigo de vida. }\end{array}$ \\
\hline Maior & 4 & $\begin{array}{l}\text { Acidentes graves de trabalho, destruição do habitat, } \\
\text { grandes emissões do efeito estufa, diminuição da } \\
\text { retenção de água e porosidade do solo causando } \\
\text { pequenos deslizamentos, erosões e inundações pouco } \\
\text { recorrentes. Perigo de morte. }\end{array}$ \\
\hline Catastrófico & 5 & $\begin{array}{l}\text { Grandes deslizamentos, inundações, grandes erosões e } \\
\text { depósito de sedimentos nos canais fluviais. Perigo a } \\
\text { vida humana. }\end{array}$ \\
\hline
\end{tabular}

Fonte: ALMEIDA et al., 2013

A partir da classificação qualitativa é feito um estudo de caso para a probabilidade de ocorrência dos eventos descritos (Quadro 6), tendo como base ocorrências passadas e sendo feita numa escala de 1 a 5 variando de raro para quase certo.

Quadro 6 - Probabilidade de ocorrência.

\begin{tabular}{|c|c|l|}
\hline Frequência & Nível & Critérios \\
Quase certo & 5 & $\begin{array}{l}99 \% \text { de possibilidade de ocorrência durante o tempo de } \\
\text { vida do projeto OU ocorreu muitas vezes na história da } \\
\text { indústria, incluindo eventos altamente frequentes ou } \\
\text { contínuos. }\end{array}$ \\
\hline Provável & 4 & $\begin{array}{l}90 \% \text { de possibilidade de ocorrência durante o tempo de } \\
\text { vida do projeto OU ocorreu muitas vezes em operações } \\
\text { similares na indústria e provavelmente vai ocorrer } \\
\text { durante a atividade. }\end{array}$ \\
\hline Possivel & 3 & $\begin{array}{l}50 \% \text { de possibilidade de ocorrência durante o tempo de } \\
\text { vida do projeto OU ocorreu frequentemente na } \\
\text { indústria, possivelmente vai ocorrer durante a atividade. }\end{array}$ \\
\hline Improvável & 2 & $\begin{array}{l}10 \% \text { de possibilidade de ocorrência durante o tempo de } \\
\text { vida do projeto OU ocorreu muito poucas vezes na } \\
\text { indústria, improvável ocorrer durante a atividade. }\end{array}$ \\
\hline
\end{tabular}




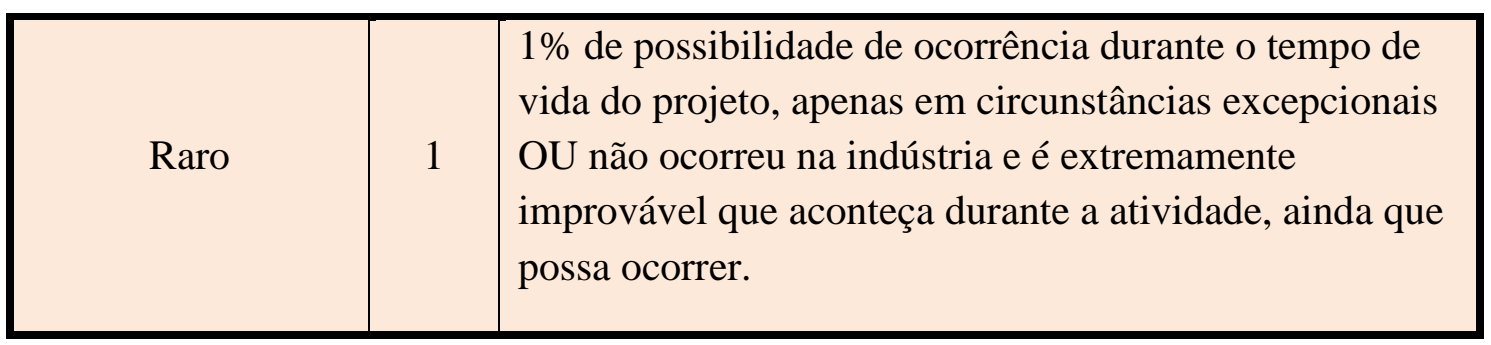

Fonte: Adaptado de MARIANO, 2007.

\section{RESULTADOS}

A partir dos quadros apresentados, é possível fazer uma estimativa e avaliação dos impactos e riscos ambientais, sendo calculado como mostrado a seguir:

\section{Impacto Ambiental = Probabilidade de ocorrência $\mathbf{x}$ Consequência}

Tendo como resultado uma matriz com valor aproximado do risco ambiental. É feita uma divisão de quatro categorias - Extremo, Alto, Moderado e Baixo - definindo os níveis de vulnerabilidade ambiental, e é inserido os resultados da matriz nessas categorias.

- Extremo - Grande risco/impacto ambiental, situação de emergência dos recursos naturais disponíveis.

- Alto - Necessária intervenção política e gerenciamento de alto nível para a redução do impacto/risco.

- Moderado - Implementação de programas de gerenciamentos futuros, e responsabilidade social, para não aumentar os impactos/riscos.

- Baixo - Aceitável, operações de rotina e manutenção, através do Plano de Gestão Ambiental e de Riscos.

Quadro 7 - Matriz Probabilidade de ocorrência x Consequência

\begin{tabular}{|c|c|c|c|c|c|}
\hline & \multicolumn{5}{|c|}{ Consequências do Evento } \\
\hline $\begin{array}{c}\text { Probabilidade } \\
\text { de Ocorrência } \\
\text { do Evento }\end{array}$ & $\begin{array}{c}\text { Insignificante } \\
(1)\end{array}$ & Menor & $\begin{array}{c}\text { Moderado } \\
(3)\end{array}$ & Maior & Catastrófico \\
$(5)$ & $(4)$ & Extremo \\
\hline $\begin{array}{c}\text { A (Quase } \\
\text { Certo) (5) }\end{array}$ & Médio & Alto & Extremo & Extremo & Ex \\
\hline
\end{tabular}




\begin{tabular}{|c|c|c|c|c|c|}
\hline & 5 & 10 & 15 & 20 & 25 \\
\hline B (Provável) & Baixo & Médio & Alto & Extremo & Extremo \\
$(4)$ & 4 & 8 & 12 & 16 & 20 \\
\hline $\begin{array}{c}\text { C (Moderado) } \\
(3)\end{array}$ & Baixo & Médio & Alto & Alto & Extremo \\
\hline $\begin{array}{c}\text { D (Improvável) } \\
(2)\end{array}$ & 3 & 6 & 9 & 12 & 15 \\
\hline E (Raro) & Baixo & Baixo & Médio & Médio & Alto \\
$(1)$ & 1 & 4 & 6 & 8 & 10 \\
\hline
\end{tabular}

No quadro 7 é apresentado o risco/impacto que pode resultar na probabilidade de ocorrência de uma determinada consequência. Multiplicando-se os fatores na matriz (Probabilidade X Consequências), verificamos que quanto maior o fator, pior será a aceitabilidade ou a vulnerabilidade do ambiente.

\section{DISCUSSÃO}

O crescimento desordenado das cidades aliado a pressão antrópica geram problemas de ordem socioambiental sabidamente conhecidos. A vegetação age como reservatório para contenção de cheias, tendo importância também na área de produção madeireira, na proteção de outros recursos naturais, bem como habitat para diversas espécies. Tendo grande papel no controle hídrico, o desmatamento, portanto, faz parte de uma importante parcela de fatores que determinam ocorrências de cheias, sendo indiretamente responsável pela erosão de solo e assoreamento de rios, sendo diretamente responsável pelo aumento de escoamento de água e aumento de nível dos cursos d'água. Tendo em vista a taxa de infiltração de água em solos florestados e descobertos, é chegada a conclusão que as cheias duram menor tempo em áreas descobertas que em áreas florestadas (ALMEIDA et al., 2013).

As ocupações urbanas e o desmatamento mais recentes de encostas de morros, causam impactos negativos a topografia, o que pode levar também a maior incidência de acidentes, 
como por exemplo, o deslizamento de solo, por conta da movimentação de terras, que diminui a estrutura natural do solo e diminuição da resistência a água, que antes era causada pelas raízes da cobertura vegetal natural (GUERRA et al., 2007).

A área estudada está localizada em um núcleo urbano de rápido crescimento populacional e pobre infraestrutura, o que faz com que a probabilidade de desastres seja mais alta do que o normal, talvez até, mais alta que a prevista em estudos anteriores. $\mathrm{O}$ desmatamento leva, quase que impreterivelmente, impactos ambientais importantes, e na maioria das vezes apresenta-se irreversível (BAPTISTA e CALIJURI, 2007; GUERRA et al., 2007; ALMEIDA et al., 2013).

\section{CONCLUSÃO}

O uso do solo urbano sofre mudanças em resposta às forças econômicas, sociais e ambientais. O gerenciamento adequado através do monitoramento e o planejamento da ocupação urbana resultam em melhores infraestruturas e em controle da expansão urbana reduzindo os impactos ambientais na região. Este gerenciamento inclui a realocação de moradias em áreas de risco e a promoção de ações socioeducativas a famílias já residentes, de modo a minimizar os impactos já ocorridos.

A sustentabilidade urbana fica então a cargo de gestores ambientais e públicos, que analisam e corroboram, quanto ao processo de planejamento urbano, as medidas preventivas e/ou corretivas que poderão ser implantadas no meio.

De acordo com a literatura consultada e a metodologia empregada, foi possível observar que os deslizamentos na região do município de Petrópolis não estão necessariamente ligados a grandes precipitações pontuais, mas sim a problemas inerentes ao balanço hídrico. Ou seja, quando há grande precipitação local e não há tempo para que a água excedente possa escoar pelas áreas subterrâneas do solo.

Esta ocorrência, de maior incidência no verão, intensifica o acúmulo de água na superfície do solo, onde a formação de sulcos no terreno pela passagem da água, aliado a declividade e ausência de cobertura, dificultam a drenagem e agem como fatores que influenciam os deslizamentos de terra que ocorrem na cidade de Petrópolis. Sendo assim, o desmatamento intensifica as consequências das grandes precipitações, logo, quanto maior o 
desmatamento, maior a probabilidade de eventos recorrentes e intensos resultantes das grandes precipitações frequentes no verão do Estado do Rio de Janeiro.

\section{REFERÊNCIAS BIBLIOGRÁFICAS}

ALMEIDA, J. R.; SILVA, C. E.; RODRIGUES, M. G.. Avaliação dos impactos ambientais do desflorestamento sobre o regime hídrico da região metropolitana de Petrópolis (RJ). Enginering Sciences, Aracaju, v. 1, n. 1, p.6-13, 31 ago. 2013. DOI: 10.6008/ess23183055.2013.001.0001. Disponível em: $<$ http://sustenere.co/journals/index.php/engineeringsciences/article/view/ESS23183055.2013.001.0001>. Acesso em: 12 jun. 2015.

BAPTISTA, A. C.; CALIJURI, M. L. Caracterização espaço-temporal por sensoriamento remoto da expansão urbana na APA Petrópolis. In: SIMPÓSIO BRASILEIRO DE SENSORIAMENTO REMOTO, 13. (SBSR)., 2007, Florianópolis. Anais do XIII Simpósio Brasileiro De Sensoriamento Remoto. São José dos Campos: INPE, 2007. p. 5091-5098. CDROM, On-line. ISBN 978-85-17-00031-7. Disponível em: 〈http://urlib.net/dpi.inpe.br/sbsr@80/2006/11.07.01.06>. Acesso em: 24 jun. 2015.

FEARNSIDE, P. M.. Desmatamento na Amazônia: dinâmica, impactos e controle. Acta Amazonica, Manaus, $\quad$ v. $\quad 36, \quad$ n. 3, p.395-400, 2006. DOI: 10.1590/s0044$59672006000300018 . \quad$ Disponível em: <http://www.scielo.br/scielo.php?script=sci_arttext\&pid=S0044-59672006000300018>.

Acesso em: 15 jun. 2015.

FERREIRA, L. V.; VENTICINQUE, E.; ALMEIDA, S.. O desmatamento na Amazônia e a importância das áreas protegidas. Estudos Avançados, São Paulo, v. 19, n. 53, p.157-166, 2005. DOI: 10.1590/s0103-40142005000100010. Disponível em: <http://www.scielo.br/scielo.php?script=sci_arttext\&pid=S0103-40142005000100010 >.

Acesso em: 15 jun. 2015.

GUERRA, A. J. T.; LOPES, P. B. M.; SANTOS FILHO, R. D.. Características Geográficas e Geomorfológicas da APA, Petrópolis. Revista Brasileira de Geomorfologia, Rio de Janeiro, v. $8, \quad$ n. $1, \quad$ p.77-86, 2007. Disponível em: <http://www.lsie.unb.br/rbg/index.php/rbg/article/view/87>. Acesso em: 15 jun. 2015.

MARIANO, J.B.. Proposta de metodologia de avaliação integrada de riscos e impactos ambientais para estudos de avaliação ambiental estratégica do setor de petróleo e gás natural em áreas offshore. 2007. 571 f. Tese (Doutorado) - Curso de Pós Graduação em Engenharia, Coordenação dos Programas de Pós-graduação de Engenharia da Universidade Federal do Rio de Janeiro (COPPE), Rio de Janeiro, 2007. Disponível em: 〈http://www.ppe.ufrj.br/ppe/production/tesis/dmarianojb.pdf $>$. Acesso em: 15 jun. 2015.

MOREIRA, I. V. D.. Avaliação De Impacto Ambiental-AIA. Rio de Janeiro: Feema, 1985. Disponível em: $\quad$ http://dgx64hep82pj8.cloudfront.net/PAT/Upload/1492611/AIA CONCEITOS.pdf>. Acesso em: 15 jun. 2015. 